\title{
As dimensões geográficas dos Arranjos Produtivos Locais ${ }^{1}$
}

\author{
Lucas Labigalini Fuini²
}

\begin{abstract}
RESUMO
O presente artigo tem como objetivo aprofundar a discussão sobre os Arranjos Produtivos Locais (APLs), considerando determinadas visões geográficas a pensar sobre a configuração espacial e os processos econômicos e sociais que os caracterizam, visto que configuram uma ampla gama de territorialidades e territórios produtivos que demarcam a paisagem brasileira atual. Nesse sentido, APLs estão presentes na atualidade tanto na figura de conceito analítico para quem estuda o desenvolvimento regional, quanto como política pública de apoio às redes e cadeias produtivas em suas bases territoriais, sobretudo de pequenos negócios. Assim, esses arranjos podem ser lidos, geograficamente, como especializações territoriais produtivas que comportan como circuitos espaciais de produção, integrados à outras regiões, localidades e cadeias produtivas através da morfologia de redes e de distritos, e alicerçados em sistemas e redes urbanas de fluxos materiais e imateriais que fazem aproximar centros urbanos de diferentes dimensões. Considerando a multidimensionalidade do tema, os APLs apresentam certas fragilidades do ponto de vista de seus postulados e perspectivas, sobretudo pelas limitações da ferramenta se pensada apenas em recursos e políticas aplicada no nível local. Sugerir a abordagem de uma "geografia dos APLs" é buscar tratá-lo a partir de uma leitura territorial e socioespacial.
\end{abstract}

Palavras chave: Arranjos produtivos locais; circuito espacial de produção; redes de distritos; rede urbana; especialização territorial produtiva.

\begin{abstract}
This article aims to further discuss the Local Productive Arrangements (APLs), considering some geographical visions thinking about spatial configuration and the economic and social processes that characterize them, configuring a wide range of territorialities and productive territories that mark the landscape current Brazilian. In this sense, APLs are present today in both the figure of those who study analytical concept for regional development, and as a public policy supporting networks and supply chains in their territorial bases, especially small businesses. Thus, this arrangements can be read, geographically, as territorial productive specializations that are configured in spatial circuits of production, integrated with other regions, localities and supply chains through the morphology of networks and districts and grounded in networks of urban networks of material and immaterial flows which are bringing urban centers of different sizes. Considering the multidimensionality of the subject, the clusters have certain weaknesses in terms of their assumptions and perspectives, especially the limitations of the tool if designed just for resources and policies applied at the local level. Suggest the approach of a "geography of APLs" is to seek treat it from a territorial and socio reading.
\end{abstract}

Key words: local productive arrangements; space circuit production; district networks; urban network; territorial productive specialization.

\footnotetext{
1 Artículo recibido el 25 de marzo de 2013, aceptado el 7 enero de 2014 y corregido el 17 de febrero de 2014.
}

\footnotetext{
2 Univesidade Estadual Paulista/UNESP (Brasil). E-mail: lucasfuini@ourinhos.unesp.br
} 
A ideia de Arranjos Produtivos Locais (APL), como política de apoio e incentivo ao desenvolvimento econômico local e regional, está associada à discussão mais ampla que envolve os modelos de aglomerações produtivas de pequenas empresas e sistemas produtivos territorializados, como os distritos industriais italianos (Becattini, 1994) e os clusters industriais (Porter, 1989), considerando a realidade brasileira. Trata-se também de uma medida de ação governamental recente no Brasil de estímulo ao desenvolvimento econômico territorial das localidades, combinando a reativação de economias de aglomeração e externas com o suporte das vocações e potencialidade regionais.

Além disso, por estabelecer uma relação entre a base produtiva e o território, o APL adquire também um caráter multidimensional, envolvendo os seguintes aspectos (IPT, 2005): a) Econômicos (ganhos em economias de aglomeração, externas, de escala e escopo); b) Geográficos (território direta ou indiretamente impactado por atores públicos e privado); c) Tecnológicos (nível tecnológico e capacidade e inovação atrelados à competitividade); d) Ambientais (contexto ambiental e os impactos indesejáveis e os ganhos do adensamento de atividades econômicas); e) Institucionais (ações de indivíduos formais e informais e organizações); f) Governança (capacidade de coordenação e comando dos agentes que interagem no aglomerado, acomodando interesses conflitantes); g) Cooperação (ações que permitem a pequenas empresas conquistarem níveis de eficiência e produtividade, tendo acesso a serviços e eventos especializados que não teriam se isoladas).

No entanto, há poucas sistematizações sobre o tema que busquem trazer para o quadro teórico da ciência geográfica a reflexão sobre esse tipo de configuração espacial (Corrêa, 2000). Assim, pensamos ser válido associar os elementos apontados como característicos para a territorialização dos APLs com determinadas categorias e teorias de corte eminentemente geográfico, buscando trazer uma contribuição original ao nosso campo de estudos com enfoque em autores brasileiros e estrangeiros.

O presente artigo tem como objetivo, portanto, aprofundar a discussão sobre os Ar- ranjos Produtivos Locais (APLs), considerando determinadas visões geográficas a pensar sobre a configuração espacial e os processos econômicos e sociais que os caracterizam, visto que configuram uma ampla gama de territórios produtivos que demarcam a paisagem brasileira atual.

De forma que podemos definir uma geografia de APLs, em aspecto amplo, como uma reflexão sobre especializações territoriais produtivas que se configuram em circuitos espaciais de produção, integrados a outras regiões, localidades e cadeias produtivas através da morfologia de redes e de distritos, e alicerçados em sistemas e redes urbanas de fluxos materiais e imateriais que fazem aproximar centros urbanos de diferentes dimensões, configurando um quadro de diferenciação territorial e de desigualdades socioespaciais que se reflete em uma heterogeneidade em relacão às condições de se produzir desenvolvimento.

Conquanto, o presente artigo se apresentado dividido em duas grandes partes: a primeira, que define conceitualmente os Arranjos Produtivos Locais, situando-os no campo analítico da epistemologia e das políticas públicas; e uma segunda parte, seccionada em subcapítulos, que visa entender, mediante determinadas teorias e modelos esquemáticos, aquilo que chamamos de esforço de geograficizar os APLs.

\section{Os APLs: Do conceito às políticas públicas}

O conceito de APL foi inicialmente sistematizado no Brasil por um grupo de pesquisadores reunidos na REDESIST (Rede de Pesquisa de Sistemas Locais de Produção e Inovação do Instituto de Economia da UFRJ), sendo posteriormente incorporado nas propostas de órgãos como o SEBRAE (Serviço Brasileiro de Apoio à Micro e Pequenas Empresas), BNDES (Banco Nacional de Desenvolvimento Econômico e Social) e ministérios e entidades públicas estaduais. Aquele grupo definia os APLs, como:

Aglomerações territoriais de agentes econômicos, políticos e sociais - com foco em um conjunto específico de atividades econômicas - que apresentam vínculos mesmo que 
incipientes. Geralmente envolvem a participação e interação de empresas - que podem ser desde produtoras de bens e serviços finais até fornecedoras de insumos e equipamentos, prestadoras de consultorias e serviços, comercializadoras, clientes, entre outros, e suas variadas formas de representação e associação. Incluem também diversas outras instituições públicas e privadas voltadas para a formação e capacitação de recursos humanos (escolas técnicas e universidades), pesquisa, desenvolvimento, engenharia, política, promoção e financiamento. Tais arranjos comumente apresentam fortes vínculos envolvendo atores localizados no mesmo território; por sua vez, as interações referem-se não apenas a empresas atuantes em diversos ramos de atividade e suas diversas formas de representação e associação (particularmente cooperativas), mas também as diversas outras instituições públicas e privadas (Cassiolato \& Lastres, 2003).

Os APLs adquirem, portanto, um caráter de plataforma de governança por conta dos vínculos cooperativos e inter-organizacionais que estabelecem em torno de um aglomerado setorial específico, que serve de base para construção de convenções e identidades comuns localizadas. Esses aglomerados têm como premissa a proximidade geográfica entre as empresas altamente especializadas que desenvolvem redes e linkages com fornecedores, firmas subcontratadas e instituições de apoio. Neste sentido, o setor e o território atuam como instâncias regulatórias importantes, definindo a governança como uma forma de coordenação do complexo industrial em sua base territorial (Pires et al., 2011).

No âmbito das políticas de desenvolvimento regional no Brasil, este parece ser um dos apelos atuais do governo federal e de alguns Estados e municípios para fortalecimento da coordenação de aglomerados produtivos e para a promoção da competitividade e desenvolvimento econômico dos territórios. Nos Planos Plurianuais do Governo federal
(2004-2007, 2008-2011 e 2012-2015), constam os APLs como eixos centrais da política industrial e de desenvolvimento regional.

Em agosto de 2004 foi instalado o Grupo de Trabalho Permanente para Arranjos Produtivos Locais - GTP APL, por Portaria Interministerial $N^{0} 200$, de 03/08/2004, envolvendo 23 instituições (Banco do Brasil, Caixa Econômica Federal, Banco do Nordeste Finep, entre outros) com o apoio de uma Secretaria Técnica lotada na estrutura organizacional do MDIC (Ministério do Desenvolvimento, Indústria e Comércio exterior), com o objetivo de adotar uma metodologia de apoio integrado a arranjos produtivos locais, com base na articulação de ações governamentais. Essa portaria foi reeditada em 24/10/2005 (com a inclusão de mais instituições), 31/10/2006 e em 24/04/2008. A atividade desse Grupo de Trabalho foi focalizada, inicialmente, em onze APLs pilotos, distribuídos nas cinco regiões do país, com o propósito de testar uma metodologia de atuação integrada.

É possível reconhecer a existência de um arranjo produtivo local a partir de um conjunto de variáveis, presentes em graus diferentes de intensidade. Pelo Termo de Referência para Política de Apoio ao Desenvolvimento dos Arranjos Produtivos Locais elaborado pelo GTP APL, um APL deve ter a seguinte caracterização: ter um número significativo de empreendimentos no território e de indivíduos que atuam em torno de uma atividade produtiva predominante e compartilhar formas percebidas de cooperação e algum mecanismo de governança. Pode incluir pequenas e médias empresas (http://www.mdic. gov.br/sitio/interna).

Ações em torno de APLs também têm merecido a atenção de outros atores e instituições como o Sebrae de apoio, financiamento e de pesquisa federais e estoduais; entre outros, conforme nos mostra o quadro abaixo (Quadro $N^{\circ} 1$ ). 
Quadro $N^{\circ} 1$

Exemplos de atuação em APLs no Brasil

\begin{tabular}{|c|c|c|}
\hline Instituições & Definição & Projetos existentes ou previstos \\
\hline $\begin{array}{l}\text { MDIC - } \\
\text { Ministério do } \\
\text { Desenvolvimento, } \\
\text { Indústria e } \\
\text { Comércio Exterior }\end{array}$ & $\begin{array}{l}\text { Um APL deve ter número } \\
\text { significativo de empreendimentos } \\
\text { no território e de indivíduos } \\
\text { que atuam em torno de uma } \\
\text { atividade produtiva predominante } \\
\text { e que compartilhem formas } \\
\text { percebidas de cooperação e } \\
\text { algum mecanismo de governança. } \\
\text { Pode incluir pequenas, médias e } \\
\text { grandes empresas. }\end{array}$ & $\begin{array}{l}\text { Juazeiro/Petrolina (fruticultura irrigada), } \\
\text { Araripina (gesso), Brasília (confecções), } \\
\text { Cachoeiro do Itapemirim (rochas } \\
\text { ornamentais), Caxias do Sul (metal- } \\
\text { mecânico), Franca (calçados masculinos), } \\
\text { Jaraguá (confecções), Nova Friburgo } \\
\text { (confecções moda íntima), Paragominas } \\
\text { (móveis), Ubá (móveis) e Apucarana } \\
\text { (confecções bonés) }\end{array}$ \\
\hline $\begin{array}{l}\text { SEBRAE Nacional } \\
\text { - Serviço } \\
\text { Brasileiro de } \\
\text { Apoio a Micro } \\
\text { e Pequenas } \\
\text { empresas }\end{array}$ & $\begin{array}{l}\text { Os Arranjos Produtivos Locais } \\
\text { são redes de empresas que } \\
\text { operam em uma determinada } \\
\text { área geográfica e colaboram } \\
\text { para conseguir maior eficiência e } \\
\text { competitividade. }\end{array}$ & $\begin{array}{l}\text { Polo moveleiro em Paragominas - PA, o } \\
\text { distrito calçadista de Campina Grande - PB, } \\
\text { o pólo de moda íntima em Nova Friburgo } \\
\text { - RJ, o polo de confecções e artesanato de } \\
\text { Tobias Barreto - SE, Polo de horticultura do } \\
\text { Agreste - AL. }\end{array}$ \\
\hline SEBRAE/SP & $\begin{array}{l}\text { Arranjos Produtivos Locais são } \\
\text { aglomerações de empresas } \\
\text { localizadas em um mesmo } \\
\text { território, que apresentam } \\
\text { especialização produtiva e } \\
\text { mantêm vínculos de articulação, } \\
\text { interação, cooperação e } \\
\text { aprendizagem entre si e com } \\
\text { outros atores locais, tais } \\
\text { como: governo, associações } \\
\text { empresariais, instituições de } \\
\text { crédito, ensino e pesquisa. }\end{array}$ & $\begin{array}{l}\text { Jaú (Calçados femininos), Birigui (calçados } \\
\text { infantis), Franca (calçados masculinos), Porto } \\
\text { Ferreira (cerâmica), Ibitinga (artigos de cama, } \\
\text { mesa e banho), de Tabatinga (confecções de } \\
\text { bicho de pelúcia e enxoval), Novo Horizonte } \\
\text { (confecções), Cerquilho/Tietê (confecção } \\
\text { infantil), S.J. do Rio Preto (equipamentos } \\
\text { médico-odontológicos), Limeira (folheados), } \\
\text { ABC (metal-mecânico, móveis e plásticos), } \\
\text { Itatiba e Mirassol (móveis), região de } \\
\text { Americana (têxtil e confecção) }\end{array}$ \\
\hline $\begin{array}{l}\text { FIESP - Federação } \\
\text { das Indústrias do } \\
\text { Estado de São } \\
\text { Paulo }\end{array}$ & $\begin{array}{l}\text { Uma concentração espacial e } \\
\text { setorial de empresas e instituições } \\
\text { que se inter-relacionam, dando uma } \\
\text { característica dinâmica própria de } \\
\text { uma determinada região. }\end{array}$ & $\begin{array}{l}\text { Ibitinga (confecções), Mirassol (móveis), } \\
\text { Limeira (Bijuterias), Vargem Grande do Sul, } \\
\text { Tambaú, Tatuí e Itu (Cerâmica Vermelha), e } \\
\text { São José do Rio Preto (Jóias). }\end{array}$ \\
\hline $\begin{array}{l}\text { Secretaria de } \\
\text { Desenvolvimento } \\
\text { do Estado de São } \\
\text { Paulo }\end{array}$ & $\begin{array}{l}\text { Os Arranjos Produtivos Locais } \\
\text { (APLs) se caracterizam por ser } \\
\text { uma concentração geográfica } \\
\text { de um número significativo } \\
\text { de empresas, principalmente } \\
\text { pequenas e médias, de um } \\
\text { mesmo setor ou mesma cadeia } \\
\text { produtiva, que mantêm algum } \\
\text { vínculo de cooperação entre si } \\
\text { e com outros agentes públicos e } \\
\text { privados. }\end{array}$ & $\begin{array}{l}\text { Americana (têxtil e confecções), Birigui } \\
\text { (calçados infantis), Cerquilho/Tietê } \\
\text { (confecções), Diadema (cosméticos), } \\
\text { Franca (calçados masculinos), Grande ABC } \\
\text { (transformados plásticos e metal-mecânico), } \\
\text { Holambra (flores), Ibitinga (bordados } \\
\text { de cama, mesa e banho), Itu (cerâmica } \\
\text { vermelha), Jaú (calçados femininos), Limeira } \\
\text { (semi-jóias), Mirassol (móveis), Panorama } \\
\text { (cerâmica vermelha), Piracicaba (cadeia do } \\
\text { etanol), RM de São Paulo (móveis), Ribeirão } \\
\text { Preto (equipamentos médico-odontológicos), } \\
\text { Santa Cruz do Rio Pardo (Couro e Calçados), } \\
\text { São José do Rio Preto (Jóias de ouro), São } \\
\text { José dos Campos (aeroespacial), Tabatinga } \\
\text { (artefatos têxteis/pelúcias), Tabatinga, Tatuí e } \\
\text { Vargem Grande do Sul (cerâmica vermelha) }\end{array}$ \\
\hline
\end{tabular}


Continuação Quadro Nº 1

\begin{tabular}{|c|c|c|}
\hline Instituições & Definição & Projetos existentes ou previstos \\
\hline $\begin{array}{l}\text { Codevasf - } \\
\text { Companhia de } \\
\text { Desenvolvimento } \\
\text { do Vale do Rio } \\
\text { São Francisco e } \\
\text { Parnaíba }\end{array}$ & $\begin{array}{l}\text { É caracterizada por ter um } \\
\text { número significativo de } \\
\text { empreendimentos no território } \\
\text { e de indivíduos que atuam em } \\
\text { torno de uma atividade produtiva } \\
\text { predominante, que compartilhem } \\
\text { formas percebidas de cooperação } \\
\text { e algum mecanismo de } \\
\text { governança e podendo incluir } \\
\text { pequenas, médias e grandes } \\
\text { empresas. }\end{array}$ & $\begin{array}{l}\text { Aquicultura (norte de Minas Gerais, oeste } \\
\text { da Bahia, lago de Sobradinho, lago de } \\
\text { Itaparica, baixo São Francisco, centro-sul } \\
\text { e oeste do Piauí), Apicultura (Norte de } \\
\text { Minas, Ibotirama/BA, Araripe/Moxotó/S. } \\
\text { Francisco/PE, Juazeiro/BA, Baixo S. } \\
\text { Francisco em Sergipe e Alagoas, Piauí), } \\
\text { Ovinocaprinocultura (Norte de Minas, } \\
\text { oeste da Bahia, microrregião de Juazeiro/ } \\
\text { BA, Pajeú/S.Francisco/Araripe/PE, Sertão } \\
\text { sergipano e alagoano, Piauí), Bovinocultura } \\
\text { (Brasilândia) e Fruticultura (pólo Petrolina e } \\
\text { Juazeiro). }\end{array}$ \\
\hline Sebrae/MG & $\begin{array}{l}\text { São aglomerações de empresas } \\
\text { localizadas em um mesmo } \\
\text { território, que apresentam } \\
\text { especialização produtiva } \\
\text { e mantêm algum vínculo } \\
\text { de articulação, interação, } \\
\text { cooperação e aprendizagem } \\
\text { entre si e com outros atores locais } \\
\text { tais como governo, associações } \\
\text { empresariais, instituições de } \\
\text { crédito, ensino e pesquisa. } \\
\end{array}$ & $\begin{array}{l}\text { Macrorregião Sul: TI-Tecnologia da } \\
\text { Informação, Malharia Retilínea, Móveis } \\
\text { e Laticínios, Macrorregião Leste: Móveis, } \\
\text { Suinocultura, Confecção e Aço Inox, } \\
\text { Macrorregião Centro: Calçados, Confecção, } \\
\text { Fogos de Artifício, Rochas Ornamentais, } \\
\text { Petróleo e Gás e Fundição, Macrorregião } \\
\text { Oeste: Cerâmica, Fruticultura, Confecção e } \\
\text { Aço Inox, Macrorregião Norte: Fruticultura, } \\
\text { Cachaça e Gemas e Jóias. }\end{array}$ \\
\hline $\begin{array}{l}\text { IEL - Instituto } \\
\text { Euvaldo Lodi } \\
\text { (Sistema FIEP- } \\
\text { Federação das } \\
\text { Indústrias do } \\
\text { Estado do Paraná) }\end{array}$ & $\begin{array}{l}\text { Termo que se usa para definir uma } \\
\text { aglomeração de empresas com a } \\
\text { mesma especialização produtiva } \\
\text { e que se localiza em um mesmo } \\
\text { espaço geográfico. }\end{array}$ & $\begin{array}{l}\text { Estado do Paraná: Apucarana (bonés), } \\
\text { Arapongas (móveis), Cascavel/Toledo } \\
\text { (equipamentos e implementos agrícolas), } \\
\text { Campo Mourão (equipamentos médico- } \\
\text { odontológicos), Cianorte (confecções), } \\
\text { Curitiba (equip. médico-odontológicos), } \\
\text { Imbituva (malhas), Loanda (metais } \\
\text { sanitários), Londrina (softwares), Paranavaí } \\
\text { (mandioca), Ponta Grossa (móveis de metal), } \\
\text { R.M. Norte de Curitiba (cal e calcário), } \\
\text { Sudoeste do Paraná (confecções), Terra } \\
\text { Roxa (confecção infantil), União da Vitória } \\
\text { (madeira e esquadrias) }\end{array}$ \\
\hline $\begin{array}{l}\text { Rede Baiana de } \\
\text { APLs } \\
\text { (Interinstitucional, } \\
\text { envolvendo } \\
\text { Secretarias } \\
\text { estaduais, } \\
\text { Fapesb, Sebrae, } \\
\text { Desenbahia e IEL) }\end{array}$ & $\begin{array}{l}\text { São caracterizados por uma } \\
\text { estreita cooperação entre } \\
\text { governo, universidades, } \\
\text { órgãos de pesquisas, órgãos } \\
\text { de financiamento, centros } \\
\text { de treinamento e apoio } \\
\text { administrativo, todos em torno } \\
\text { das empresas, na busca de } \\
\text { resultados concretos que visam } \\
\text { a geração de renda, emprego e } \\
\text { conseqüentemente à melhoria das } \\
\text { condições de vida da população. }\end{array}$ & $\begin{array}{l}\text { Confecções (Salvador), Rochas ornamentais } \\
\text { (Ourolândia), Ferramentaria (Região } \\
\text { metropolitana de Salvador), Cachaça } \\
\text { (Abaíra-Chapada da Diamantina), Flores } \\
\text { (Maracás), Plásticos (RMS - Polo de } \\
\text { Camaçari), Sisal (Valente), Cerâmica } \\
\text { Estrutural (Alagoinhas) }\end{array}$ \\
\hline
\end{tabular}


Continuação Quadro N 1

\begin{tabular}{|c|c|c|}
\hline Instituições & Definição & Projetos existentes ou previstos \\
\hline $\begin{array}{l}\text { Redesist (Rede } \\
\text { de Pesquisa } \\
\text { em Sistemas } \\
\text { e Arranjos } \\
\text { produtivos } \\
\text { e inovativos } \\
\text { locais) - Envolve } \\
\text { universidades } \\
\text { e centros de } \\
\text { pesquisa no } \\
\text { Brasil- Sede no } \\
\text { IE-UFRJ }\end{array}$ & $\begin{array}{l}\text { São aglomerações territoriais de } \\
\text { agentes econômicos, políticos } \\
\text { e sociais, com foco em um } \\
\text { conjunto específico de atividades } \\
\text { econômicas e que apresentam } \\
\text { vínculos de interdependência. } \\
\text { Geralmente envolvem a } \\
\text { participação e a interação de } \\
\text { empresas - que podem ser } \\
\text { desde produtoras de bens e } \\
\text { serviços finais até fornecedoras } \\
\text { de insumos e equipamentos, } \\
\text { prestadoras de consultoria e } \\
\text { serviços, comercializadoras, } \\
\text { clientes, entre outros - e suas } \\
\text { variadas formas de representação } \\
\text { e associação. Incluem também, } \\
\text { diversas outras instituições } \\
\text { públicas e privadas voltadas } \\
\text { para: formação e capacitação } \\
\text { de recursos humanos, como } \\
\text { escolas técnicas e universidades; } \\
\text { pesquisa, desenvolvimento e } \\
\text { engenharia; política, promoção e } \\
\text { financiamento. }\end{array}$ & $\begin{array}{l}\text { Acre (Indústrias Florestais-Xapuri), Amazonas } \\
\text { (Floricultura-Manaus), Pará (Floricultura e } \\
\text { Círio de Nazaré), Maranhão (Turístico-S. } \\
\text { Luís), Piauí (Apicultura), Ceará (Pingo } \\
\text { d'água, Ovinocaprinocultura, Turismo } \\
\text { religioso-Juazeiro do Norte), R. G. do Norte } \\
\text { (Têxtil-Natal, Bordados-Caicó), Paraíba } \\
\text { (Coureiro-calçadista, confecções e S. João- } \\
\text { Campina Grande), Sergipe (Confecções- } \\
\text { Tobias Barreto), Bahia (Cacau-Sul baiano, } \\
\text { Petróleo e Gás-Recôncavo, Confecções e } \\
\text { TI), Goiás (Confecções-Jaraguá, Turismo- } \\
\text { Pirenópolis), Mato Grosso do Sul (Mandioca- } \\
\text { Sul, Turismo-Bonito/Bodoquena), Minas } \\
\text { Gerais (Automotivo/Fiat-Betim, Redes de } \\
\text { inovação-Grande BH, Calçadista-Nova } \\
\text { Serrana, Moveleiro-Ubá), Espírito Santo } \\
\text { (Siderurgia, Madeira, Metal-mecânico } \\
\text { e Rochas ornamentais), Rio de Janeiro } \\
\text { (Têxtil-confecções, Softwares, Música- } \\
\text { Conservatória, Rochas ornamentais), } \\
\text { São Paulo (Móveis, Aeronáutico-S.J. dos } \\
\text { Campos, Base tecnológica-S. Carlos, } \\
\text { Telecomunicações-Campinas) Paraná } \\
\text { (Soja, Inovação), Santa Catarina (Têxtil/ } \\
\text { vestuário-Vale do Itajaí, Softwares-Joinvile, } \\
\text { Turismo-Florianópolis, Cerâmica-Criciúma) } \\
\text { e Rio Grande do Sul (Vinho, Fumageiro, } \\
\text { Moveleiro-Serras Gaúchas, Máquinas e } \\
\text { implementos agrícolas). }\end{array}$ \\
\hline
\end{tabular}

Fonte: Elaborado pelo autor (fontes diversas).

É possível afirmar que existem APLs em diferentes estágios de coordenação produtiva e institucional, refletindo cada qual com o nível econômico, social e tecnológico adequado ao seu contexto regional e setorial. Santos et al. (2002) estabelecem uma classificação para os APLs situados em ambientes periféricos, construindo um modelo analítico que caracteriza a situação de aglomeração, arranjo potencial e, em perfil mais restrito, a noção de Arranjo produtivo local (Quadro $N^{\circ} 2$ ).

Em complemento, faz-se necessária a consideração de que o debate sobre APL e o uso dessa ferramenta como estratégia para organização de políticas públicas de desenvol- vimento não é unanimidade no pensamento acadêmico. Alguns autores, como Brandão et al. (2006) criticam a aposta excessiva em modelos de desenvolvimento territorial como Distritos Industriais e Arranjos Produtivos Locais, pois concebem neles: a) apologia ao $10-$ calismo e ao desenvolvimento endógeno para desenvolver regiões periféricas, deixando de lado a relação supralocal das redes econômicas globais; b) fragilidade institucional de modelos de arranjos de micro e pequenos negócios, subordinados aos outros níveis político-administrativos (Estadual, Federal); c) associação dos interesses privados e empresariais (competitividade) com o interesse público, sobretudo em regiões com alta especialização produtiva. 
Quadro $N^{\circ} 2$

As vantagens competitivas locacionais em aglomerações e APLs

\begin{tabular}{|c|c|}
\hline Formatos empíricos de APLs & Vantagens competitivas de APLs \\
\hline 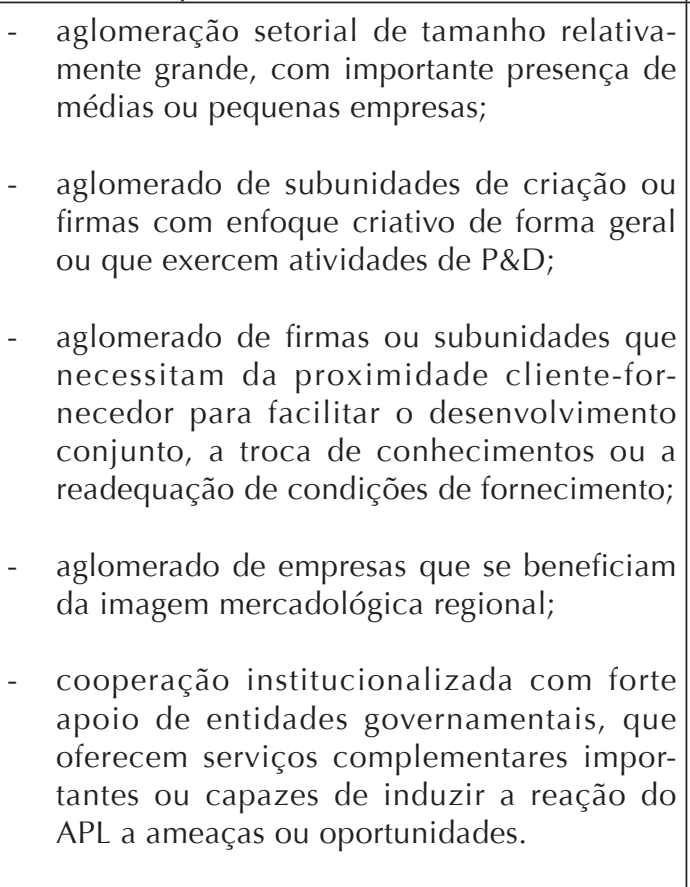 & 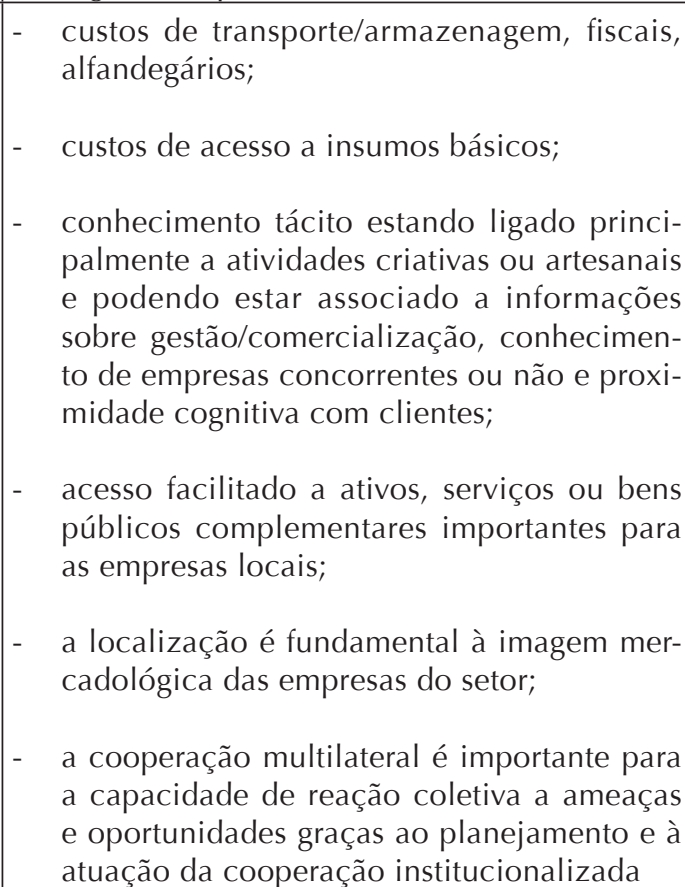 \\
\hline
\end{tabular}

Fonte: adaptado de Santos et al. (2004).

Além disso, Cocco et al. (2002) chamam atenção para a dificuldade em relação à adaptação de modelos de desenvolvimento local, como o dos Distritos industriais italianos, para a realidade brasileira:

O modelo explicativo sobre a evolução dos distritos industriais, ao ressaltar o caráter espontâneo de sua formação e sucesso competitivo, não apresenta espaços de intervenção de poderes públicos em regiões onde as atividades produtivas são difusas e marginais (quanto à inovação, gestão e inserção em mercados), onde não existam, portanto, clusters setoriais minimamente consolidados, como ocorre geralmente nas periferias das metrópoles brasileiras ou em inúmeros pequenos municípios do interior do país.

Fugindo aos extremos, devemos considerar os APLs, primeiramente, como expressões da realidade socioeconômica que se manifestam no território brasileiro por meio de aglomerações regionais de pequenos empreendimentos setoriais que aparecem como possíveis elementos de dinamismo ao mercado de trabalho e ao sistema econômico. Os APLs também não excluem outros formatos de políticas de desenvolvimento, aparecendo em alguns contextos como estratégias complementares, em outros podem ser as estratégias centrais. Além disso, formatos de Arranjos e Distritos necessitam de políticas não somente locais ou municipais, mas também do apoio estadual e nacional, já que muitos instrumentos administrativos, financeiros e institucionais não são regulados no local.

\section{Compreensões geográficas sobre APLs}

Como é um tema recorrente na agenda política brasileira, a discussão sobre Arranjo Produtivo Local (APL) ainda carece de rigor teórico e de embasamento científico, estando muito associada aos manuais e agendas de 
órgãos e serviços públicos e privados. Buscando aprofundar essa discussão, expomos a seguir uma tentativa de estabelecer nexos conceituais e teóricos entre as compreensões mais gerais de APL com outros conceitos e noções já trabalhados e aprofundados na Geografia econômica e urbana, considerando a importância desse esforço de análise como mais um elemento para a sistematização de idéias e informações sobre o tema em análise.

\section{A concepção de Arranjos Produtivos Locais como Circuito espacial de produção}

Os APLs podem ser entendidos como "circuitos espaciais de produção", na concepção de Santos \& Silveira (2010). Os circuitos de produção surgem quando as aglomerações setoriais desenvolvem, no espaço geográfico, redes mais ou menos densas de fluxos de matérias-primas, produtos, informações, que se estruturam em uma escala regional. Os circuitos espaciais de produção podem ser definidos pelo movimento de trocas e fluxos de bens e serviços entre lugares especializados através da segmentação territorial das etapas do trabaIho, em áreas não necessariamente contíguas.

Este movimento não é apenas material e, envolve também fluxos de informações e ordens que caracterizam os "círculos de cooperação", as dimensões regulatórias de um "circuito produtivo".

“(...) cada lugar é alvo de sucessivas divisões do trabalho. Mas esse lugar, visto num corte temporal, (...), acolhe simultaneamente várias divisões do trabalho, e como estas não se realizam independentemente dos fluxos, superpõe-se no lugar simultaneamente várias divisões do trabalho e (...) circuitos da produção. Criam-se, assim, solidariedades entre elementos

Figura $\mathrm{N}^{\circ} 1$

Modelo esquemático de Circuitos espaciais de produção e Círculos de cooperação

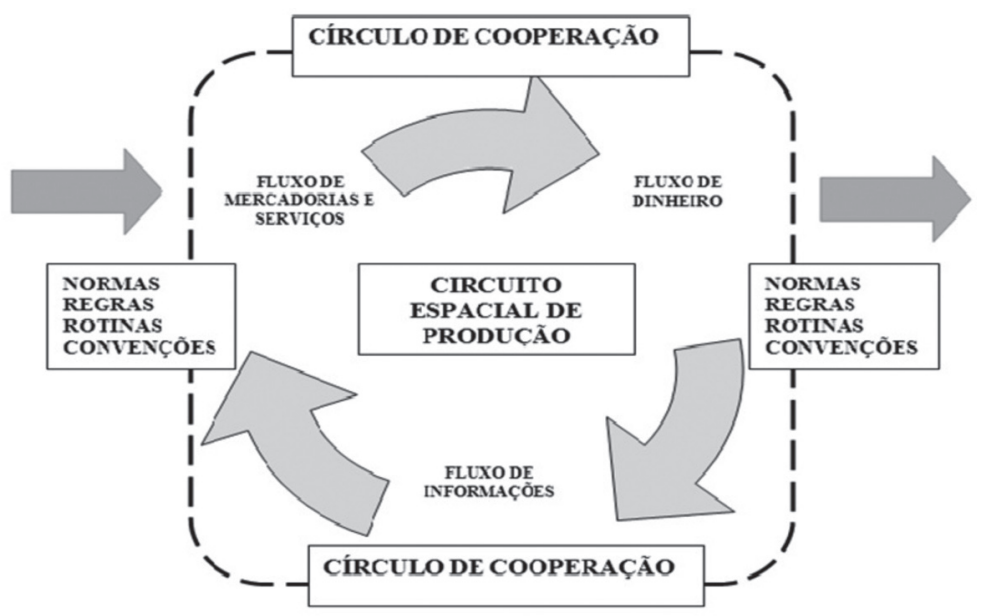

Fonte: Elaboração própria.

novos e herdados. Circuitos espaciais de produção e círculos de cooperação mostram o uso diferenciado de cada território por parte das empresas, das instituições, dos indivíduos e permitem compreender a hierarquia dos lugares desde a escala regional até a mundial" (Santos \& Silveira, 2010).
No caso de APLs, os circuitos espaciais de produção correspondem ao conjunto formado por empresas, serviços correlatos (educacionais, financeiros, consultorias técnicas), poder público e associações representativas que realizam trocas entre si e com outras localidades através do fluxo de mercadorias, informações de contratantes e 
fornecedores, matérias-primas, finanças etc. O círculo de cooperação, por seu turno, se refere ao conjunto de normas, regras e rotinas que caracterizam a interação entre empresas, instituições, trabalhadores e consumidores, aparecendo como o mecanismo regulatório do aparelho produtivo. Cooperar aqui passa por um acontecer comum e pela construção de projetos compartilhados de concertação e de governança de territórios.

\section{A concepção de Arranjos Produtivos Locais como "redes de distritos" ou "distritos em rede"}

Os APL podem se comportam morfologicamente, em termos econômicos e espaciais, como uma rede de aglomerações produtivas localizadas e conectadas por comandos regidos pela lógica dos fluxos econômicos e não econômicos; com incidência sobre as infra-estruturas urbanas e de circulação em determinada região.

Os distritos industriais são formas de organização espacial das atividades industriais credenciados no passado a servirem como símbolos de um novo modelo de produção, desenvolvimento e regulação chamado de "especialização flexível", emergente a partir de fins dos anos 1970.

Pode-se definir o distrito industrial como a entidade socioterritorial que se caracteriza pela presença ativa de uma comunidade humana e de uma população de empresas em um espaço geográfico e histórico. No distrito, a comunidade e as empresas tendem a se reunir. Na reflexão marshalliana, e nos ensinamentos de seus sucessores Becattini, Bagnasco, Brusco, Trigala, Bellandi, Sforzi, Garofoli, etc., o distrito industrial tem conotação setorial, mas não significa que seja homogêneo. O distrito industrial marshalliano é o lugar onde se reúnem condições de densidade de população, de infra-estrutura e de 'atmosfera industrial' que são, ao mesmo tempo, a causa e o efeito de parte dos rendimentos crescentes (economias externas locais) que não se explica nem pelas economias de escala nem pelas características materiais das novas tecnologias (Benko, 1996: 229).

Os distritos industriais definem também uma nova estratégia de desenvolvimento, baseada em formas de regulação intermediárias e nas energias, recursos e modalidades de organização econômica e política locais, chamado de desenvolvimento local ou regional endógeno. A literatura sobre os distritos deve muito de seu destaque à contribuição de teóricos italianos que reconheceram em distritos industriais da Terceira Itália, entre os anos 1960 e 1980, exemplos bem sucedidos economicamente e cujo sucesso se atribuía ao modo de regulação estabelecido, misto de concorrência, cooperação e estímulo e baseado em alianças entre empresários, assalariados e coletividades locais. Esse modelo, reconhecido internacionalmente, passou a servir de ferramenta de análise de diversos casos de aglomerações de empresas espalhadas pelo mundo, inclusive no Brasil, com a adoção da terminologia de Arranjos Produtivos Locais.

Benko (1996), ao analisa a emergência de formas de regulação intermediárias, nem estritamente mercantis nem estritamente estatais, evidencia a transição de um modelo de rede para um modelo de distrito. A rede, nesta concepção, é a forma de organização interempresarial que envolve relações de hierarquia ou de cooperação em parceria. Tratase um tipo de organização industrial baseado na conjunção da autonomia de gestão das unidades econômicas e de sua cooperação rotinizada, dependendo das formas técnicas, social (rede de transportes e comunicação), de organização e de interface daquilo que deve ser coordenado, compensando a perda de certas vantagens de aglomeração devido à distância.

Considerando, então, a existência de diversas formas de coordenação das redes de empresas, Benko (1996) identifica e qualifica duas possibilidades de configuração socioespacial: a) A rede de distritos (Figura $\mathrm{N}^{\circ} 2$ ), evocada quando se trata de indústrias que baseiam suas atividades em duas ou mais cidades, alimentando uma rede de fluxos de insumos e componentes para a montagem do produto final; b) Os distrito de redes (Figura $N^{\circ} 3$ ): aglomeração de vários ramos da indústria em uma região, mantendo constantes relações transacionais umas com as outras, tendo em comum um mercado de mão-de-obra e de profissionais qualificados. Trata-se de uma aglomeração de indústrias qualificadas por sua proximidade e tipo social comum. 
Figura $\mathrm{N}^{\circ} 2$

Modelo de redes de Distritos

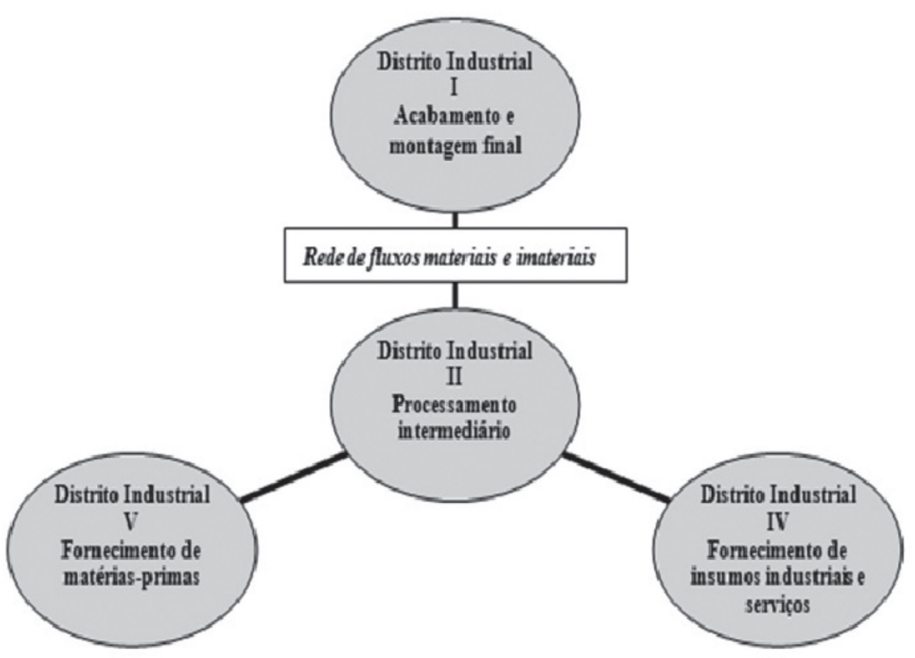

Fonte: Elaboração própria.

Figura $\mathrm{N}^{\circ} 3$

O modelo de Distritos de redes

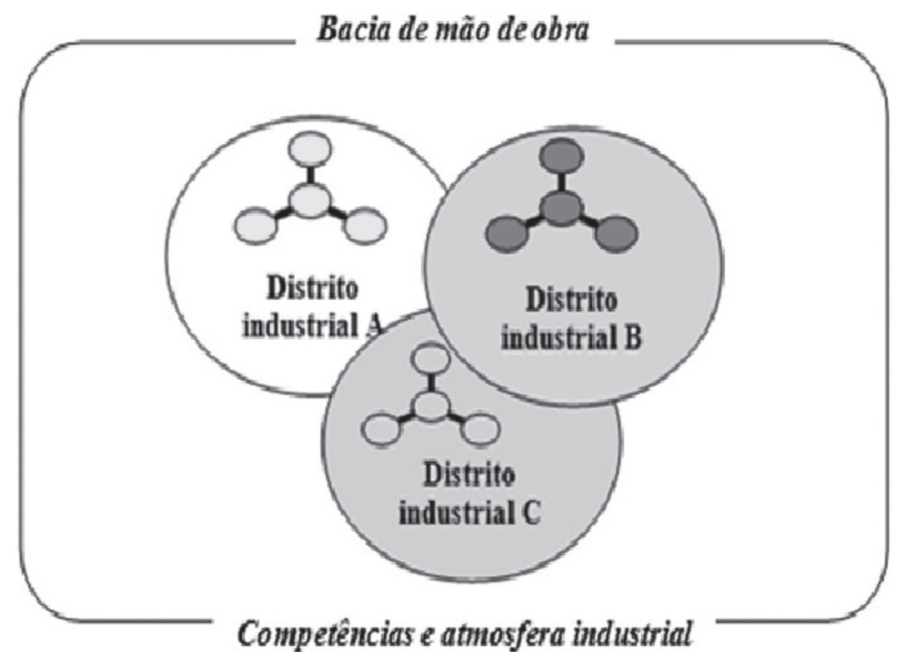

Fonte: Elaboração própria.

As morfologias de "redes de distritos" e de "distritos de redes" podem ser aplicadas ao estudo de APLs na medida em que estes envolvem diferentes formas de relacionamento entre áreas produtoras e aglomerações industriais e de serviços, dentro da territorialidade de uma cadeia produtiva integrada por determinadas estruturas de governança.
Conforme o tipo de articulação e organização das redes socioeconômicas e técnicas, o APL pode ser o contexto de ocorrência de dois ou mais subaglomerados de atividades econômicas complementares e setorialmente próximos, mesmo que alocado cada um deles em uma municipalidade específica. Ao mesmo tempo, APLs podem também justapor 
atividades bastante dispares, como a produção artesanal lado a lado à grande indústria de transformação. Aparece assim o arranjo, como um distrito de redes que se justapõe locacionalmente para o aproveitamento de algum recurso genérico ou específico territorialmente delimitado.

\section{A concepção de Arranjos Produtivos Locais como Rede urbana}

Corrêa (2006) define a rede urbana como um conjunto articulado de centros urbanos diferenciados, que é, ao mesmo tempo, reflexo, meio e condição social. Historicamente, passou a ser o meio através do qual a produção, circulação e consumo se realizam efetivamente, sendo a infraestrutura material indispensável à economia globalizada.

O conjunto de centros urbanos funcionalmente articulados entre si apresenta uma diferenciação entre suas cidades, traduzida em uma hierarquia urbana de acordo com os princípios gerais da teoria das localidades centrais e, não necessariamente, de acordo com a especialização funcional (...) Esse conjunto de centros hierarquizados e especializados constitui-se na estrutura territorial onde se dá a criação, apropriação e circulação do valor excedente (Corrêa, 2006: 45).

Neste sentido, a rede urbana apresenta as seguintes características:

a) É um reflexo da divisão territorial do trabalho: em razão das vantagens locacionais diferenciadas, verifica-se uma hierarquia urbana e uma especialização funcional caracterizadora de cidades industriais, político-administrativas ou portuárias. Além disso, é reflexo à medida que os efeitos acumulados da prática de diferentes agentes sociais, sobretudo grandes corporações multifuncionais e multilocalizadas, introduzem na cidade e no campo atividades que geram diferenciação entre os centros;

b) É condição para a divisão territorial do trabalho: a cidade, em suas origens, foi também um ponto no espaço geográfico que, através da expropriação de excedentes agrícolas, passou a controlar a produção rural e esse controle foi transmitido progressivamente à rede urbana. Além disso, através das funções articuladas de suas cidades (bancos, comércio atacadista e varejista, indústrias e serviços de transportes, armazenagem, contabilidade, educação, etc.) a rede urbana é também uma condição, viabilizando: a produção das áreas pastoris, de mineração e industriais; a circulação e o consumo entre elas; decisões, investimentos e inovações, criando a transformando atividades e cidades;

c) É uma forma espacial: pode ser vista como expressão fenomênica particular de processos sociais que se realizam em um amplo território envolvendo mediações diversas que se verificam nas cidades, desempenhando funções inerentes ao processo de criação, apropriação e circulação do valor excedente na estrutura do capitalismo. As formas espaciais da rede urbana podem ser simples ou complexas;

d) Pode ser periodizada: como um tipo de organização espacial, a rede urbana pode ser periodizada, pois, envolve uma sequência de combinações desiguais das diferentes instâncias da totalidade social (econômica, jurídico-política e ideológica). A periodização é uma operação intelectual que permite definir os tempos históricos no qual o pesquisador torna inteligível a forma específica da totalidade social

Nesse sentido, é necessário que se apreenda sobre a rede urbana, acerca de sua gênese (condições internas e externas, papel dos diferentes agentes, articulação intra e interregional, forma inicial e funcionalidade), dinâmica social (mudança e permanências das formas espaciais, articulações, agentes e condições) e o processo de mudança em marcha. Corrêa (2006) sugere para a abordagem geográfica da rede urbana, o estudo das seguintes dimensões: atração da população rural, drenagem urbana da renda fundiária, comercialização da produção agrícola, investimentos e criação de trabalho pela cidade, relações interindustriais e distribuição de bens e serviços.

O APL sempre tem como seu elemento estruturador uma rede urbana ou segmentos de uma rede (Figura $N^{\circ} 3$ ), sendo que o fluxo de trocas de produtos, serviços e finanças 
constitui uma rede de municípios, de porte variável. Esses municípios, explorando suas potencialidades econômicas, utilizarão a in- fraestrutura de transportes regional para fazer movimentar suas economias e alimentar o dinamismo dos empreendimentos locais.

Figura $\mathrm{N}^{\circ} 4$

Rede urbana subjacente às aglomerações produtivas

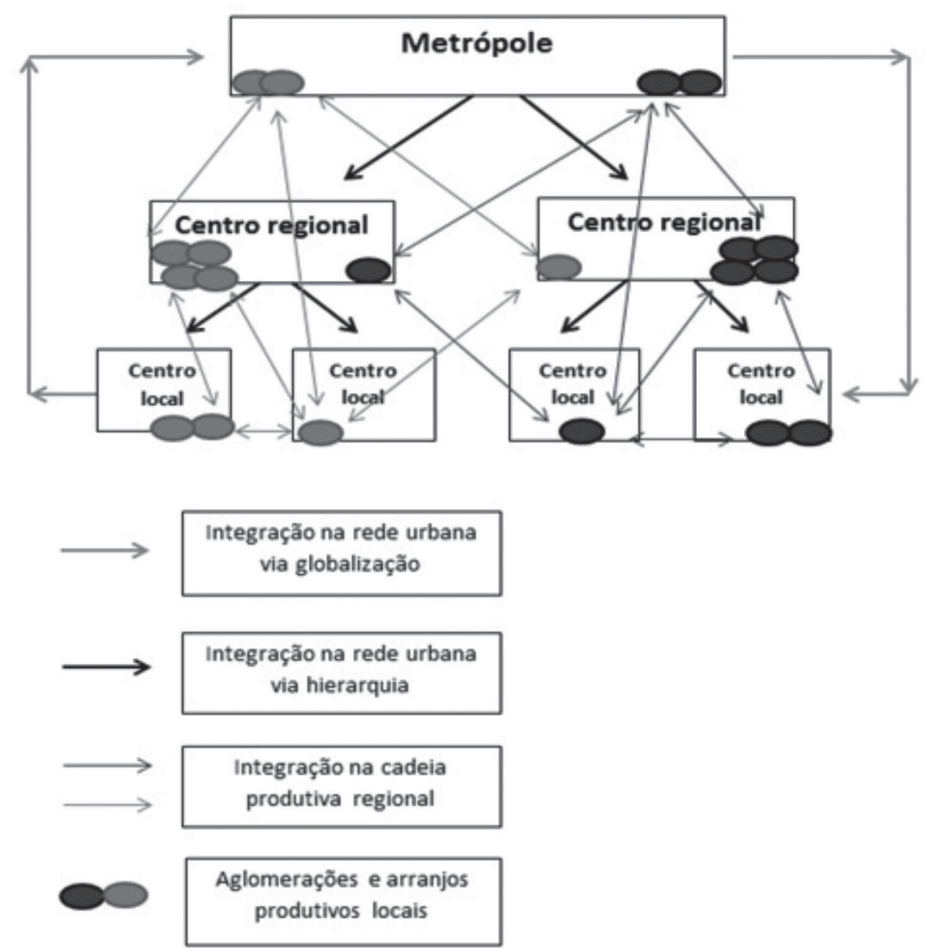

Fonte: Elaboração própria.

Esse posicionamento hierárquico da rede urbana influencia também o posicionamento dos municípios no interior do arranjo, evidenciando a primazia na produção interna e na densidade de técnica e capital de algumas cidades sobre outras, refletindo essa hierarquia sobre a governança e comando do processo produtivo em relações desiguais de poder.

A compreensão de APLs como especializações territoriais produtivas

A divisão territorial do trabalho conduz crescentemente os lugares, no período de globalização econômica, à especialização de suas produções. Silveira (2011) entende a especialização territorial produtiva como a agregação de atividades similares ou complementares sobre um mesmo lugar, seja no campo, com novos lençóis agrícolas globalizados, seja nas cidades, consagradas a certo tipo de produção industrial ou a um conjunto de produções. Ao lado da especialização se coloca também a diversidade territorial produtiva, que a autora define como uma base socioespacial caracterizada pelo sistema produtivo criado em determinado lugar ou área e seus elos da cadeia de produção, além das interdependências em um mesmo ramo da 
economia formadas pelo conjunto definido pelas economias de aglomeração e as especializações produtivas em regiões e lugares.

Esse diversidade ou diferencial territorial pode também ser traduzida como as desigualdades territoriais, se considerarmos os diferentes dinamismos entre territórios. Assim, essas desigualdades derivam das características naturais herdadas, das condições materiais de modificação do espaço geográfico e das diferenças de densidade técnicas e organizacionais entre recortes espaciais usados e apropriados (Santos e Silveira, 2010). Essas desigualdades podem reativar, para seu entendimento, uma nova lógica de relação centro-periferia, pautada na divisão técnica e territorial do trabalho, ou uma relação entre concentrações de capitais regionais (culturais, científicos, técnicos, meios financeiros) e as estruturas sociais, funcionais e político-administrativas das cidades (Benko, 1996). Assim, as desigualdades territoriais se apresentam, espacialmente, através da seguinte explicação de Silveira (2011: 11).
Áreas de especialização e de diversidade poderiam ser entendidas como um tecido no qual as condições locais de infraestrutura, recursos humanos, fiscalidade, organização sindical, força reivindicatória afastam ou atraem atividades num dado momento. Quando o poder público promove poucas atividades oligopolizadas, o território vê transformar-se recursos em ativos circunscritos e limitados a um pequeno número de atores. Desse modo, cresce a vulnerabilidade do território e da sociedade e a riqueza se concentra. Talvez um caminho para transformar essa situação seja formular as políticas públicas que, considerando que o território usado é plural, possam assegurar a possibilidade de existência de todos os atores.

Santos e Silveira (2010) reconhecem que a especialização do trabalho nos lugares é um dos elementos do período atual fundado em uma nova divisão territorial do trabalho, ao lado de outros elementos: progressos da ciência e técnica e circulação acelerada das informações e a ocupação de áreas perifé-

Figura $\mathrm{N}^{\circ} 5$

O modelo de relações de divisão territorial do trabalho entre áreas produtivas especializadas

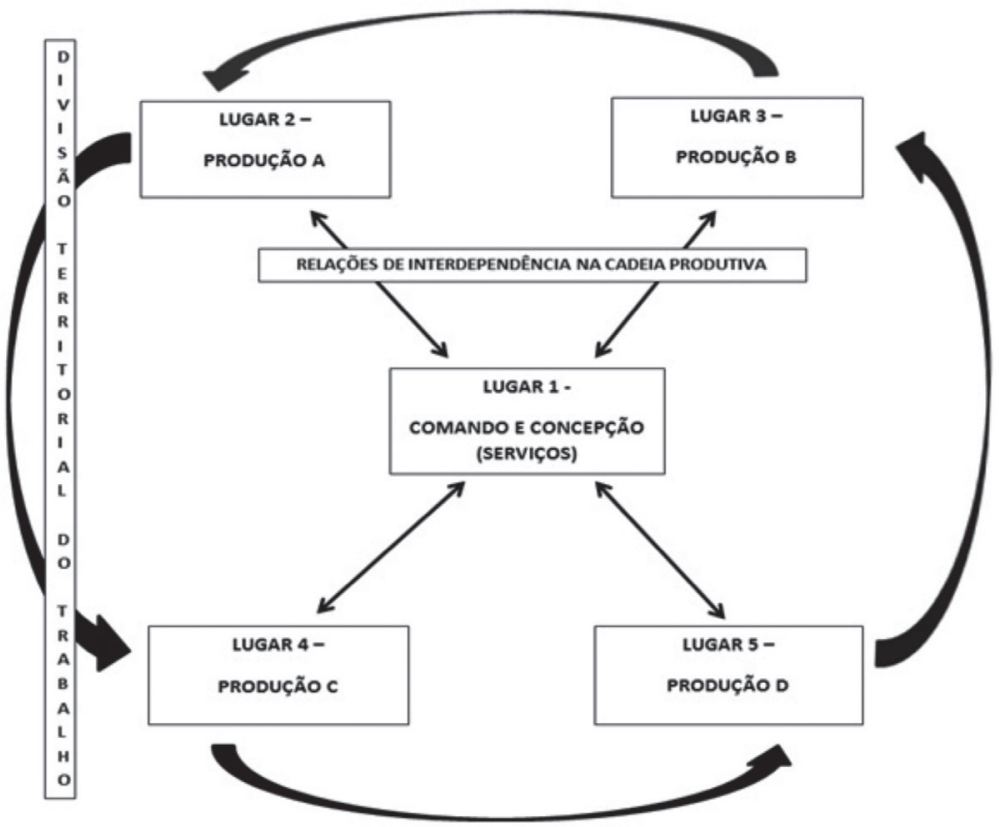

Fonte: Elaboração própria. 
ricas para o capitalismo e remodelação de áreas já ocupadas. Assim, a construção de especializações (industriais, comerciais e de serviços) leva à segmentação e fragmentação territorial, pois ao mesmo tempo em que se alargam os contextos para a circulação entre pontos do território, as regiões perdem o comando sobre o que nelas acontece.

Os APLs são reconhecidos pelos elementos de aglomeração e especialização produtiva em territórios locais e regionais específicos. Um dos principais elementos de especialização de APLs seria sua forte identificação com concentrações em sistemas de micro e pequenas empresas, que devido às suas limitações em economias de escala e externalidades, se agrupam e se associam para ter acesso a determinados serviços e investimentos. Outro nível de especialização premente é aquele relacionado aos segmentos e elos de cadeias produtivas industriais e de serviços territorializados, permitindo ganhos de escala e escopo devido aos conhecimentos e saberes locais historicamente sedimentados em torno de determinadas atividades (Garofoli, 1994).

A superespecialização produtiva territorial, no entanto, envolve riscos associados à dependência econômica crescente de localidades e regiões em relação a determinados segmentos industriais, agroindustriais e de serviços que podem sofrer com crises conjunturais ou estruturais, micro ou macroeconômicas. Outra ordem de problemas é em relação à fragmentação territorial em regiões especializadas e dependentes, em termos tecnológicos e financeiros, de cadeias de valor concentradas por grandes grupos globais que operam a partir de outras regiões ou países e que determinam as normas e ordens do sistema econômico em nível mundial (Santos, 2001).

\section{Considerações finais}

O presente artigo traz a preocupação de se buscar no conhecimento geográfico contribuições para a melhor compreensão sobre o tema de pesquisa e objeto político dos Arranjos Produtivos Locais. Pelo exposto, observamos que a temática apresenta as características da multidimensionalidade de aspectos envolvidos em sua definição e da diversidade territorial de esquemas de organização para seu desenvolvi- mento em casos identificados e/ou incentivados para funcionarem como APL.

Além disso, o tema apresenta certas fragilidades do ponto de vista de seus postulados e perspectivas, sobretudo pelas limitações da ferramenta se pensada apenas em recursos e políticas aplicada no nível local. Além disso, a simples transposição de categorias criadas em outros contextos, como os Distritos Industriais italianos, mostraram-se insuficientes para o entendimento da lógica setor-terriório presente em ambientes de arranjos produtivos em países e regiões periféricas.

No entanto, como dado da realidade, um evento ou forma de configuração espacial, os Arranjos Produtivos Locais nos dão pistas para um maior aprofundamento de seu estudo dentro das categorias analíticas da Geografia, considerando a atualidade do tema e sua já expressiva representação em diversos Estados, regiões e municípios brasileiros.

Mormente interpretado pelos vieses econômico e da administração de empresas e incorporados aos estudos espaciais, pensamos a partir desse esforço de análise sugerir uma Geografia dos APLs, ou propor que se trate o tema em sua lógica territorial e socioespacial. Mas, sabemos que esse esforço ainda é incompleto e que outras teorias e perspectivas podem contribuir para completar e explicar esse "mosaico de regiões produtivas especializadas, com processos complexos de crescimento localizado, cada vez mais dependentes das outras regiões" (Benko, 1996: 68).

\section{Referências bibliográficas}

BECATTINI, G.O. Distrito Marshalliano: Uma noção sócio-econômica. In: BENKO, G.E. \& LIPIETZ, A (organizadores). As Regiões Ganhadoras. Distritos e Redes: Os novos paradigmas da Geografia Econômica. Oeiras: Celta Editora, 1994, p. 45-58.

BENKO, G. Economia, Espaço e Globalização: na aurora do século XXI. São Paulo: Hucitec, 1996.

BENKO, G. e PECQUEUR, B. Os recursos da territórios e os territórios de recursos. Geosul, 2001, Vol. 16, No 32, p. 31-50. 
CASSIOLATO, J.E. \& LASTRES, H.M.M. O foco em Arranjos produtivos e inovativos locais de micro e pequenas empresas. In: LASTRES, H.M.M.; CASSIOLATO, J.E. \& MACIEL, M.L. (organizadores). Pequena empresa: cooperação e desenvolvimento local. Rio de Janeiro: Relume Dumará, 2003, p. 21-34.

COCCO, G.; URANI, A.; GALVÃO, A. P. \& PEREIRA DA SILVA, M. C. Desenvolvimento local e espaço público na Terceira Itália: Questões para a realidade brasileira. In: COCCO, G.; URANI, A. \& GALVÃO, A. P. Empresários e empregos nos novos territórios produtivos: O caso da Terceira Itália. Rio de Janeiro: DP\&A/Sebrae, 2002, p. 13-26 .

CORRÊA, R.L. Estudos sobre a Rede Urbana. Rio de Janeiro: Bertrand Brasil, 2006.

CORRÊA, R.L. Região e organização espacial. São Paulo: Nobel, 2000.

GAROFOl, G. Os Sistemas de Pequenas Empresas: Um Caso Paradigmático de Desenvolvimento Endógeno. In: BENKO, G. \& LIPIETZ, A (organizadores). As Regiões Ganhadoras. Distritos e Redes: Os novos paradigmas da Geografia Econômica. Oeiras: Celta Editora, 1994, p. 203-217.

INSTITUTO DE PESQUISAS TECNOLÓGICAS. As dimensões dos Arranjos Produtivos Locais. Texto de divulgação interna. São Paulo: IPT, 2005, p. 1-34.

MINISTÉRIO DO DESENVOLVIMENTO, INDÚSTRIA E COMÉRCIO EXTERIOR (MDIC). Termo de referência para a política de apoio aos Arranjos Produtivos Locais. Brasília: Departamento de Competitividade Industrial, 2008. Disponible en Internet: http:// www.mdic.gov.br/sitio/interna
PIRES, E.L.S.; FUINI, L.L.; MANCINI, R.F. \& PICCOLI NETO, D. Governança territorial: Conceito, fatos e modalidades. Rio Claro: Unesp-IGCE-Programa de Pós-graduação em Geografia, 2011.

PORTER, M. Competição: Estratégias competitivas essenciais. Rio de Janeiro: Campus -Elsevier, 1999.

RAFFESTIN, C. Por uma geografia do poder. São Paulo: Ática, 1993.

SANTOS, F.; CROCCO, M.A. \& LEMOS, M.B. Arranjos e sistemas produtivos locais em espaços industriais periféricos: Estudo comparativo de dois casos brasileiros. Belo Horizonte: UFMG/Cedeplar, 2002.

SANTOS, G.A.G.; DINIZ, E.J. \& BARBOSA, E.K. Aglomerações, Arranjos Produtivos Locais e Vantagens Competitivas Locacionais. Revista do BNDES, 2004, Vol. 11, N²2, p. 151-179.

SANTOS, M. A natureza do espaço: técnica, tempo, razão e emoção. São Paulo: Aucitec, 1996.

SANTOS, M. Por uma outra globalização: Do pensamento único à consciência universal. São Paulo/Rio de Janeiro: Record, 2001.

SANTOS, M. \& SILVEIRA, M.L. O Brasil: Território e Sociedade no início do século XXI. Rio de Janeiro-São Paulo: Record, 2010.

SILVEIRA, M.L. Território usado: Dinâmicas de especialização, dinâmicas de diversidade. Ciência geográfica, 2011, Vol. 15, No 1, p. 4-12. 
